\title{
CRIAÇÃO E DESTRUIÇÃO DE EMPREGO NA INDÚSTRIA E OS EFEITOS DO CÂMBIO E DA ABERTURA COMERCIAL: O CASO DA INDÚSTRIA GAÚCHA NOS ANOS 1990*
}

\author{
Eduardo Pontual Ribeiro ${ }^{\S}$ \\ Filipe Keuper Rodrigues Pereira ${ }^{\circ}$
}

\begin{abstract}
RESUMO
A compreensão da dinâmica do emprego é um ponto importante na agenda de pesquisa e política econômica. Este artigo busca trazer maiores evidências sobre o seu comportamento, estudando, primeiro, os fluxos de emprego na indústria, tomando o caso do Rio Grande do Sul nos anos 1990; e, segundo, o efeito do câmbio e da abertura comercial sobre estes fluxos. Quanto aos fluxos, identificamos uma significativa heterogeneidade entre as empresas estudadas, em que, dentro de cada setor, há criação e destruição simultânea de postos de trabalho, mesmo quando de forte retração do emprego setorial e agregado. Quanto ao efeito do câmbio e da abertura, depreciações reduzem a destruição e aumentam a criação de emprego de modo simétrico, levando a uma criação líquida de emprego, sem influenciar a realocação de postos de trabalho. Uma maior abertura leva à expansão do emprego, por efeito de redução da destruição. O efeito da abertura é menor que o efeito do câmbio e de choques de demanda, sugerindo que a abertura em si não foi a grande responsável pela redução do emprego industrial na década de 1990, em nossa amostra.
\end{abstract}

Palavras-chave: emprego industrial, criação e destruição de emprego, abertura comercial, câmbio.

\begin{abstract}
The goal of this article is to study job and worker flows in manufacturing and the effect of trade liberalization, looking at the case of Rio Grande do Sul State in the 1990's. Job flows suggest significant heterogeneity and that within each sector there is simultaneous job creation and destruction. Regarding the effect of the exchange rate and trade liberalization, depreciation reduces job destruction and increase job creation symmetrically, leading to net job growth. Yet, there is no effect on job reallocation. Greater openness expands manufacturing by reducing job destruction. The effect of the exchange rate and demand shocks are larger than the effect of trade openness, suggesting that trade liberalization was not the main reason for manufacturing employment contraction over the period.
\end{abstract}

Key words: manufacturing employment, job creation and destruction, trade liberalization, exchange rate.

JEL classification: F40, J60.

\footnotetext{
* Esta pesquisa teve apoio da FAPERGS e do CNPq. Parte deste trabalho foi escrita quando o primeiro autor era professor visitante Fundação Ford na ENCE/IBGE. Agradecemos a hospitalidade e acesso à infra-estrutura computacional. Por fim, agradecemos à FIERGS que generosamente permitiu acesso aos dados.

§ IE/UFRJ, PPGE/UFRGS e Pesquisador CNPq. E-mail: eribeiro@ie.ufrj.br. End. para correspondência: IE / UFRJ - Av. Pasteur, 250, Térreo, Urca, Rio de Janeiro, RJ, 22290-240, tel. (21) 3873-5246.

a PPGE/UFRGS e University of Illinois, EUA. E-mail: fsr@decon.ufpe.br.

Recebido em abril de 2005. Aceito em julho de 2006.
} 


\section{INTRODUÇÃO}

A década de 1990 significou, para o Brasil, um período de intensas mudanças institucionais, econômicas e tecnológicas. Das mudanças ocorridas na última década, a redução das tarifas de importação está entre os processos mais marcantes do período, quando a tarifa média de 67,8\% em 1985 reduziu-se para 10,4\% em 1993, de acordo com Kume, Piani e Souza (2000). Além da abertura, também foram acentuadas as mudanças da taxa de câmbio do País, em especial a mudança do regime cambial em 1994 e sua desvalorização em janeiro de 1999, com a mudança para o regime de câmbio flutuante. Juntos, esses dois fatores tornaram os anos 1990 um período especialmente rico para o estudo do impacto do comércio exterior (câmbio e importações e exportações) no emprego.

Do lado do emprego, a década de 1990 foi marcada por uma retração significativa do emprego industrial, no Brasil e no Rio Grande do Sul. Os dados da nossa amostra indicam uma queda no emprego de mais de 10\% entre 1991 e 1998, com uma forte reversão no ano de 2000. Diante da mudança significativa da tendência do emprego após a mudança cambial, pode-se levantar a hipótese de que o câmbio possui um efeito muito forte, possivelmente maior que a abertura econômica sobre o emprego industrial.

O nível do emprego (ou desemprego) e suas variações são referenciais tradicionais e muito utilizados como parâmetros na avaliação da realidade do mercado de trabalho e de suas oscilações. Por outro lado, a análise do nível e da taxa de emprego agregado pode esconder importantes informações sobre o mercado de trabalho. A decomposição desta em taxas referentes aos postos que estão sendo criados ou destruídos permite uma análise mais detalhada da dinâmica e da turbulência nos movimentos de trabalhadores em sua busca ou realocação dentro de - e entre - diferentes atividades. Por exemplo, mesmo em períodos de recessão, há empresas em expansão e contratando, e em períodos de crescimento, há empresas em retração ou fechando, ou seja, destruindo postos de trabalho.

Trabalharemos aqui com a decomposição da taxa de variação do emprego em taxas de criação e taxas de destruição do emprego no Rio Grande do Sul, dentro da literatura de fluxos de postos de trabalho (job flows), que atraiu grande interesse nos últimos anos. O objetivo é avaliar especificamente o impacto das variações do câmbio e da abertura nessas taxas nesse Estado. A hipótese assumida é que mudanças da taxa de câmbio são uma fonte de choques que implicam mudanças nos preços relativos e que, portanto, implicam realocação dos fatores de produção, como o emprego. Em síntese, entendemos os choques advindos do câmbio como choques relocativos.

A importância do impacto do câmbio está diretamente relacionada ao nível de abertura comercial na economia, pela presença de produtos importados ou destinados à exportação. Num setor como o de Material Elétrico e de Comunicação, por exemplo, em que o nível médio de penetração das importações foi estimado em $58 \%$ para nossa base de dados, as variações da taxa de câmbio exercem, em princípio, maior impacto nos preços relativos do que num setor como o de bebidas, no qual o nível médio de penetração das importações na década de 1990 foi estimado em 2,5\%.

Para a investigação dos efeitos do câmbio no emprego usamos uma amostra de empresas pesquisadas pela Federação das Indústrias do Estado do Rio Grande do Sul (FIERGS). Desde 1991, sob a coordenação da CNI, são coletadas diversas variáveis - dentre as quais pessoal ocupado - para a Pesquisa Indicadores Industriais CNI. A periodicidade de coleta é mensal e aproximadamente 200 empresas de uma amostra intencional são acompanhadas. A base de dados tem como principal vantagem a possibilidade de acompanhar empresas ao longo do tempo, na forma de um painel.

O trabalho está sistematizado da seguinte forma. Após apresentar as definições referentes à criação de emprego (JC) e destruição de emprego (JD) e a base de dados em si, apresentamos fatos 
estilizados para os fluxos de postos de trabalho na Indústria Gaúcha. Em seguida, revisamos a relação entre comércio exterior com a taxa de crescimento do emprego, assim como sua relação com JC e JD. A última seção apresenta e discute os resultados, na literatura, sobre os efeitos do câmbio em JC e JD, assim como apresenta um modelo para descrever essas relações e os resultados da implementação empírica.

\section{CRIAÇÃO E DESTRUIÇÃO DE EMPREGO: DEFINIÇÕES E DADOS}

Neste trabalho, um emprego é considerado como uma posição ocupada por um trabalhador. $\mathrm{Na}$ base de dados empregada no trabalho, a informação de que dispomos é a relativa ao número de empregados no último dia do mês. A decomposição da taxa de variação líquida do emprego em taxas de criação e destruição de emprego implica novas definições e conceitos para a análise dos dados. Nesta seção serão expostas e explicadas as principais definições a serem utilizadas no trabalho. Seguimos aqui as definições de Davis et al. (1996), as mais usadas na literatura.

Definimos o crescimento do emprego $n_{i t}$ na firma i no período $t$ como $g_{i t}=\left(n_{i t}-n_{i t-1}\right) / x_{i t}$, em que $x_{i t}=\left(n_{i t}+n_{i t-1}\right) / 2$. Dividindo a variação pela média dos dois períodos torna a taxa de crescimento simétrica em torno de zero e a restringe a valores finitos ( -2 a 2), aspecto particularmente importante quando do nascimento de uma firma. Desde o artigo de Davis e Haltiwanger (1992), esta fórmula de cálculo tem sido empregada amplamente na literatura. Pode-se demonstrar que $G=2 g /(2-g)$, em que $G_{i t}=\left(n_{i t}-n_{i t-1}\right) / n_{i t-1}$ é a taxa de variação porcentual normalmente estimada.

A taxa de criação de empregos de um setor ou indústria (JC) é definida como a soma (ponderada pelo tamanho da firma em número de empregados) das taxas de crescimento não negativas das firmas na amostra $(i=1, \ldots, \mathrm{N})$ pertencentes àquele grupo:

$$
J C_{t}=\sum_{i=1}^{N} g_{i t} w_{i t} I\left(g_{i t} \geq 0\right)
$$

em que $w_{i t}=x_{i t} /\left(\sum_{i=1}^{N} x_{i t}\right)=x_{i t} / X_{t}$ é o peso de cada firma e $I($ ) é a função indicador, que toma valor 1 se o critério é verdadeiro e 0 se falso. De modo simétrico, a taxa de destruição de postos de trabalho (JD) pode ser definida como a soma ponderada das taxas de crescimento negativas das firmas na amostra $(i=1, \ldots, \mathrm{N})$ :

$$
J D_{t}=\sum_{i=1}^{N}\left|g_{i t}\right| w_{i t} I\left(g_{i t}<0\right)
$$

A taxa de variação líquida do emprego, à qual também chamaremos de NEG (Net Employment Growth), é dada por:

$$
N E G_{t}=\sum_{i=1}^{N} g_{i t} w_{i t}=J C_{t}-J D_{t}
$$

Aqui se torna mais claro o que foi mencionado na introdução: a decomposição que essas taxas representam da variação líquida do emprego. Uma variação líquida negativa na taxa de emprego de $1 \%$ pode estar associada a diferentes medidas de criação e destruição: $0 \%$ e $1 \%, 5 \%$ e $6 \%, 20 \%$ e $21 \%$, por exemplo. No entanto, mesmo o resultado líquido sendo análogo, estas diferentes taxas que compõem a variação líquida representam realidades muito diferentes no mercado de trabalho. Enquanto no primeiro exemplo (nenhum emprego criado e $1 \%$ destruídos) a turbulência e o custo de 
realocação é o menor possível, no terceiro exemplo o custo e o nível de incerteza para os trabalhadores na mesma queda de $1 \%$ do emprego são maiores. Além disso, para uma determinada taxa de crescimento líquido do emprego, maiores taxas de criação de emprego tornam mais fácil a alocação para quem está desempregado ou entrando no mercado de trabalho, ao passo que maiores taxas de destruição de emprego implicam menor nível de segurança para trabalhadores empregados. Dessa forma, a criação e a destruição abrem uma nova perspectiva sobre a dinâmica do trabalho encoberta pelas estatísticas agregadas no mercado de trabalho.

As medidas referentes à criação e à destruição do emprego nos permitem também efetuar estimativas sobre as transições de trabalhadores no mercado de trabalho, induzidas por mudanças na distribuição de postos de trabalho na economia. Entretanto, a nossa análise é limitada às variações líquidas do emprego nas empresas, posto que não há informações sobre o número de trabalhadores contratados e desligados ao longo do período. Como limite inferior dessas transições, ou seja, da rotatividade, a taxa de realocação bruta do emprego, GJR (Gross Job Reallocation) é dada pela soma de JC e JD:

$$
G J R_{t}=J C_{t}+J D_{t}=\sum_{i=1}^{N}\left(\left|n_{i t}-n_{i t-1}\right| / X_{t}\right)
$$

A realocação bruta de emprego é uma maneira útil de sintetizar a heterogeneidade das mudanças no nível de emprego nas firmas, contabilizando o aumento de empregos que aparece nas firmas em expansão e a redução que ocorre nas empresas em contração. Para acomodar as mudanças naturais que ocorrem na taxa de variação líquida do emprego pode haver criação ou destruição de emprego, ou ambos, e GJR capta especificamente essa medida. Entretanto, quando há criação e destruição de postos de trabalho simultaneamente, existe um nível de realocação bruta além do estritamente necessário, dado pela diferença entre a realocação e o valor absoluto da taxa de variação líquida do emprego. Como afirmam Corseuil et al. (2002), essa medida explica o quanto da rotatividade não pode ser explicado pela necessidade de crescimento (ou redução) líquida do emprego:

$$
E J R_{t}=G J R_{t}-\left|N E G_{t}\right| .
$$

Os dados utilizados neste trabalho foram obtidos na FIERGS - Federação das Indústrias do Rio Grande do Sul, oriundos da pesquisa Indicadores Industriais CNI. Desde janeiro de 1991, sob a coordenação da CNI, são coletados dados das indústrias gaúchas com o objetivo de acompanhar seu desempenho, especialmente a curto prazo. A base apresenta duas vantagens que merecem destaque: sua periodicidade ser mensal e a amplitude das informações coletadas.

As unidades de coleta são empresas e filiais sediadas no Rio Grande do Sul. A matriz, desde que localizada no Estado, responde as informações referentes a si própria e às suas filiais no Estado. Filiais cujas matrizes localizam-se fora do Estado também são incluídas na amostra, sendo que as informações coletadas são concernentes exclusivamente a elas (as filiais). ${ }^{1}$ As unidades estão agrupadas em 16 setores ou gêneros industriais: Metalúrgica, Mecânica, Material Elétrico e de Comunicações, Material de Transporte, Madeira, Mobiliário, Borracha, Couros e Peles, Química, Têxtil, Vestuário e Calçados, Produtos Alimentares, Bebidas, Editorial e Gráfica e Diversas. ${ }^{2}$ A

1 Em outras palavras, a amostra não é composta apenas por empresas, havendo dados de estabelecimentos localizados no Rio Grande do Sul, de empresas com sede fora do Estado. Como as taxas de fluxos de trabalhadores são menores para dados em empresas, em relativamente a dados de estabelecimentos, por não serem computadas nas primeiras as transferências entre filiais da mesma empresa, é possível que estejamos subestimando os fluxos de emprego, em relação a uma amostra de dados de estabelecimentos apenas.

2 O setor de Fumo foi excluído por apresentar características próprias que o diferenciam dos outros setores, particularmente um comportamento sazonal extremo. 
base abrange o período de janeiro de 1991 a junho de 2001. As informações são mensais, e os dados sobre emprego referem-se ao pessoal ocupado com vínculo empregatício no último dia de cada mês.

Na amostra não é possível contabilizar a entrada e saída (nascimentos e mortes) das firmas. Desta forma, como não é possível saber se uma firma que passou a responder é nova ou apenas foi incluída na amostra (e, da mesma forma, se uma firma que deixou de responder o fez por decisão própria, falência ou cisão), todas as estatísticas são calculadas para as empresas quando se tem a informação disponível em no mínimo dois períodos consecutivos. Quando se trata de dados anuais, o número médio de empresas por ano é de 355.

Como a seleção da amostra é intencional ${ }^{3}$ comparativamente à PIA, parece haver um viés para médias e grandes empresas: além de estarem em maior número, correspondendo a 67,18\% das empresas na nossa base, juntas respondem por 97,32\% do pessoal ocupado, enquanto que nos cálculos com os dados da PIA estas somam 82,03\% do pessoal ocupado. Por outro lado, o viés para grandes e médias empresas implica que estaremos acompanhando a dinâmica da maior parte dos postos de trabalho e empregos considerados por muitos como de melhor qualidade (em termos de rendimentos e benefícios) em relação a pequenas e médias empresas. O viés para grandes empresas é verificado em outros trabalhos, como Konings (1996).

\section{FATOS ESTILIZADOS DA CRIAÇÃO E DA DESTRUIÇÃO DO EMPREGO NA INDÚSTRIA NO RIO GRANDE DO SUL}

A Tabela 1 apresenta um resumo de estatísticas descritivas das taxas de criação de emprego, destruição de emprego, da realocação bruta, da variação líquida e da realocação de emprego em excesso (limite superior). As taxas foram calculadas com os dados anuais, referentes ao último dia de dezembro de cada ano. ${ }^{4}$

A taxa líquida de variação do emprego na nossa amostra é, em média, de $-0,40 \%$ ao ano no período de 1991 a 2000. Esse valor médio ao longo de 9 anos representa uma queda acentuada do nível de emprego na indústria do Rio Grande do Sul. Subjacente a essa queda mensal, o nível de realocação (limite inferior da rotatividade) é estimado em 12,56\% ao ano. Isto significa que, aproximadamente, pelo menos um em cada oito postos de trabalho nas empresas presentes na nossa amostra é criado ou destruído por ano. Como era de se esperar, a taxa de destruição de 6,48\% ao ano é superior à taxa de JC, de 6,08\% ao ano. Comparando apenas 1992 a 1998, a queda é de $-1,52 \%$ ao ano ou $10,5 \%$ no período.

A Tabela 1 evidencia ainda o baixo desvio padrão derivado dos valores anuais de GJR $(2,46 \%)$ quando comparado com o desvio padrão da variação líquida da taxa de emprego (4,19\%). Enquanto a GJR situa-se entre os valores de 9,24\% e 17,14\%, um intervalo de 7,90\%, o NEG varia de $-5,42 \%$ a $6,53 \%$, um intervalo de $11,95 \%$. O acompanhamento da tabela sugere que, independentemente da variação líquida da taxa de emprego, a realocação é elevada: enquanto de 1992 a 2000 o NEG variou, assumindo diversos níveis, a realocação esteve sempre acima de 10\%, excetuando-se o ano de 1998, quando esteve em 9,24\%. A alta realocação pode ser identificada pela realocação em excesso (EJR), que teve valor médio de 9,23\%. Ou seja, esta foi a proporção de empregos em excesso que mudou de empresa devido à necessidade de ajuste agregado do emprego industrial.

3 Para mais detalhes, veja CNI: Notas metodológicas da pesquisa de indicadores conjunturais. www.cni.org.br.

4 As taxas também foram calculadas com os dados mensais e trimestrais, referente ao último dia do mês corrente e último mês do trimestre, respectivamente. Na análise dos dados anuais as variações sazonais deixam de ter reflexo nas estatísticas. 
Em termos de dinâmica, verifica-se que a destruição é mais volátil que a criação de emprego. Vemos, com isso, que a realoação parece ser anticíclica. Esta característica, verificada para a indústria dos EUA (Davis et al. 1996), sugere que períodos de queda do emprego são caracterizados por um aumento da destruição maior que a redução da criação de empregos. O comportamento relativamente mais estável da criação de emprego em relação à destruição ao longo do ciclo econômico é compatível com modelos de destruição criativa para explicar a dinâmica econômica.

A última linha da Tabela 1 mostra que grande parte da heterogeneidade das taxas de variação do emprego na empresa não é explicada por características setoriais. Em outras palavras, as diferenças entre empresas de um mesmo setor são bem maiores que as diferenças médias setoriais, pois em um modelo de regressão em que explicamos a dinâmica da criação, destruição e realocação em função do ciclo econômico (medido pela variação do emprego líquido), dummies setoriais explicam não mais que $13 \%$ das medidas de variação bruta do emprego. Todas estas evidências sugerem que modelos baseados em agentes representativos, ou que consideram a indústria e seus subsetores como homogêneos (no sentido de as empresas que compõem os setores terem o mesmo comportamento na média), não conseguem capturar a efetiva dinâmica do emprego da economia.

Tabela 1 - Dinâmica do emprego na indústria do RS, 1992-2000 (anual)

\begin{tabular}{lccccc}
\hline Ano & JC & JD & NEG & GJR & EJR \\
\hline 1992 & 0.0538 & -0.0845 & -0.0307 & 0.1383 & 0.1076 \\
1993 & 0.1127 & -0.0587 & 0.0539 & 0.1714 & 0.1175 \\
1994 & 0.0605 & -0.0530 & 0.0075 & 0.1135 & 0.1061 \\
1995 & 0.0501 & -0.1002 & -0.0501 & 0.1503 & 0.1001 \\
1996 & 0.0456 & -0.0633 & -0.0177 & 0.1089 & 0.0912 \\
1997 & 0.0390 & -0.0932 & -0.0542 & 0.1322 & 0.0781 \\
1998 & 0.0387 & -0.0538 & -0.0151 & 0.0924 & 0.0774 \\
1999 & 0.0567 & -0.0514 & 0.0053 & 0.1081 & 0.1028 \\
2000 & 0.0905 & -0.0252 & 0.0653 & 0.1156 & 0.0503 \\
Média & 0.0608 & -0.0648 & -0.0039 & 0.1256 & 0.0923 \\
Correlação com NEG & 0.8694 & 0.8553 & --- & 0.0548 & -0.1543 \\
$\beta x$ & $0.4000^{*}$ & $0.5999^{*}$ & & $-0.1998^{*}$ & 0.0177 \\
\% Variância de JC/JD explicada & $0.0337)$ & $(0.0337)$ & -- & $(0.0674)$ & $(0.0394)$ \\
pelo setor & 0.0883 & 0.1153 & -- & 0.1394 & 0.1920 \\
\hline
\end{tabular}

Fonte: FIERGS - Pesquisa Indicadores Industriais - CNI. Cálculos dos autores.

Nota: * significativo a 10\%. $\beta x$ é o coeficiente de regressão de um modelo de efeitos fixos de cada variável em função de NEG, usando 16 setores. Desvios padrão entre parênteses.

Tabela 2 - Dinâmica do emprego na indústria do RS, 1992-2000 (trimestral)

\begin{tabular}{lccccc}
\hline & JC & JD & NEG & GJR & EJR \\
\hline Média & 0,0261 & $-0,0270$ & $-0,0009$ & 0,0531 & 0,0395 \\
Correlação com NEG & 0,8091 & 0,8612 & -- & $-0,1568$ & 0,1212 \\
$\beta x$ & $0,5405^{*}$ & $0,4594^{*}$ & -- & $0,0810^{*}$ & $0,0603^{*}$ \\
& $(0,0161)$ & $(0,0161)$ & & $(0,0322)$ & $(0,0235)$ \\
\% Variância de JC/JD explicada & 0,1106 & 0,0586 & -- & 0,1529 & 0,1555 \\
pelo setor & & & & & \\
\hline
\end{tabular}

Fonte: FIERGS - Pesquisa Indicadores Industriais - CNI. Cálculos dos autores.

Nota: * significativo a $10 \%$. $\beta x$ é o coeficiente de regressão de um modelo de efeitos fixos de cada variável em função de NEG, usando 16 setores. Desvios padrão entre parênteses. 
Diversos autores, tanto na literatura nacional quanto internacional, têm se dedicado à estimação dessas taxas. Comparando com os resultados coletados em Davis e Haltiwanger (1999) e Ribeiro (2001), para estudos referentes à indústria e excluindo a entrada e saída de empresas, vemos que no período de 1992 a 2000 as empresas em estudo no Rio Grande do Sul tiveram uma taxa média de realocação bruta do emprego de $12,56 \%$, que não se classifica entre as taxas mais elevadas. Mesmo no Brasil, Pazello et al. (2000) estimaram essa taxa em 23,10\%. O viés da amostra para grandes empresas deve explicar grande parte da diferença, pois maiores empresas tendem a ter menor realocação.

Para avaliar a persistência da criação e destruição do emprego, a Tabela 2 apresenta os resultados para a variação bruta do emprego trimestral. Como esperado, as taxas de variação bruta de criação e destruição do emprego são menores do que as anuais, mas surpreende que a dinâmica se altere, quando passamos de dados anuais para trimestrais. Nos dados trimestrais, a criação do emprego parece ser mais volátil, implicando que a realocação de emprego seja pró-cíclica. A diferença entre as Tabelas 2 e 3 sugere que a criação do emprego é menos persistente que a destruição na indústria gaúcha. A maior parte da criação, relativamente à destruição de emprego, é revertida dentro do ano, pois a dinâmica do emprego muda quando são comparados os efeitos anuais e trimestrais.

A Tabela 3 apresenta as estatísticas estimadas de JC, JD, GJR, NEG e EJR por setor no Rio Grande do Sul. As estimativas foram elaboradas com base nos dados anuais de cada setor entre os anos de 1992 e 2000.

Entre os aspectos mais marcantes da Tabela 3 está o fato de a taxa de crescimento anual líquida do emprego em 15 dos 17 gêneros industriais ser negativa. Esta queda do emprego nos diferentes setores na indústria do Rio Grande do Sul vem ao encontro do comportamento de queda do emprego na indústria brasileira na década de 1990 e a variação média negativa verificada acima para a década.

Tabela 3 - Taxas de fluxo de emprego (\%) por setor na indústria no RS, média 1992-2000

\begin{tabular}{lccccc}
\hline Setor & JC & JD & GJR & NEG & EJR \\
\hline Metalúrgica & 3.73 & 7.28 & 11.01 & -3.55 & 5.61 \\
Mecânica & 5.25 & 7.12 & 12.38 & -1.87 & 6.94 \\
Material elétrico e de comunicações & 3.95 & 4.69 & 8.63 & -0.74 & 5.89 \\
Material de transporte & 5.91 & -5.85 & 11.76 & 0.06 & 6.58 \\
Madeira & 6.45 & -14.39 & 20.84 & -7.94 & 4.72 \\
Mobiliário & 6.51 & -6.77 & 13.29 & -0.25 & 7.57 \\
Borracha & 6.90 & -6.12 & 13.03 & 0.78 & 6.18 \\
Couros e peles & 4.02 & -6.71 & 10.73 & -2.68 & 6.91 \\
Química & 4.16 & -8.21 & 12.38 & -4.05 & 3.97 \\
Têxtil & 7.35 & -3.10 & 10.46 & 4.24 & 0.18 \\
Vestuário e calçados & 7.48 & -6.20 & 13.68 & 1.27 & 8.94 \\
Produtos Alimentares & 4.76 & 5.02 & 9.78 & -0.26 & 6.24 \\
Bebidas & 8.64 & -4.87 & 13.51 & 3.77 & 5.97 \\
Editorial e gráfica & 3.31 & -5.51 & 8.82 & -2.19 & 3.59 \\
Outros & 4.11 & -5.97 & 10.08 & -1.85 & 4.25 \\
Total na Indústria & 6.08 & -6.48 & 12.56 & -0.39 & 6.23 \\
Desvio Padrão & 1.65 & 6.33 & 2.94 & 3.05 & 2.06 \\
\hline
\end{tabular}

Fonte: FIERGS - Pesquisa Indicadores Industriais - CNI. Cálculos dos autores. 
A taxa de realocação do emprego anual agregada, estimada para a nossa amostra, é de 12,56\%. Os setores que apresentam uma taxa de realocação significativamente maior do que a média são os setores de Madeira (20,84\%), Vestuário e Calçados (13,68\%), Mobiliário (13,29\%) e Borracha $(13,03 \%)$. Para o caso de Madeira, a taxa de realocação indica que 1 em cada 5 postos de trabalho não existia ou passou a existir entre um ano e o seguinte, em média.

Ainda sobre a decomposição da taxa de crescimento do emprego em JC e JD, note que todos os setores que estão em contração no que diz respeito ao pessoal ocupado apresentam empresas que estão contratando, i.e., existe simultaneamente criação e destruição de empregos. O setor que exibe a maior queda agregada no emprego setorial, o de Madeira, apresenta uma taxa de criação de emprego de 6,45\% ao ano, em média. Mas, se por um lado existem empregos sendo criados, mesmo com o número de pessoas empregadas diminuindo no total do setor, por outro, existe um grande número de empregos sendo destruídos. Calculando-se a média anual diretamente dos setores, a taxa de JD é de 6,48\%. Isto significa que aproximadamente 6 em cada 100 empregos deixam de existir, por ano, em cada setor.

A coexistência de taxas positivas de criação e destruição de emprego simultâneas sugere uma grande heterogeneidade na dinâmica do emprego entre empresas dentro de um mesmo setor. A principal mensagem da análise é de que o exame dos dados setoriais de variação líquida do emprego omite informações importantes sobre sua dinâmica.

\section{ABERTURA COMERCIAL E A CRIAÇÃO E DESTRUIÇÃo DE EMPREGO}

O processo de abertura comercial está entre os principais fatores que caracterizaram a década de 1990 como um período de fortes mudanças na economia brasileira. Em linha com nosso objetivo de avançar no entendimento das relações entre o câmbio e a criação e a destruição de empregos na indústria do Rio Grande do Sul, e partindo-se do entendimento de que quanto maiores os níveis de importação e exportação em um país, maior é a possibilidade de que mudanças na taxa de câmbio alterem os preços relativos na economia e o nível de alocação ótima dos recursos, faz-se necessária uma revisão do processo de abertura comercial e das evidências apontadas no que diz respeito à sua relação com o emprego (seção 4.1), assim como das relações entre nível de abertura e criação e destruição do emprego (seção 4.2).

\subsection{A abertura comercial e sua relação com o emprego}

Até o final da década de 1980 a economia brasileira era praticamente fechada a produtos importados. Segundo Barros et al. (1996), em 1985, no seu ápice, a tarifa legal média era superior a $130 \%$, levando a que as importações representassem pouco mais de $4 \%$ da demanda doméstica, enquanto as exportações representavam cerca de $9 \%$ do produto nacional.

O processo de abertura comercial brasileiro somente teve início no final dos anos 1980. Este processo iniciou-se a partir da reforma tarifária de 1988, quando, também em 1989, o governo tomou as primeiras medidas de forma a tornar a estrutura tarifária mais transparente, efetuando a redução de alíquotas para o aumento da exposição da economia nacional à concorrência internacional. Dentre essas primeiras medidas foram extintas as barreiras remanescentes dos períodos anteriores, implementou-se um programa de redução generalizada de alíquotas, eliminaram-se alguns regimes aduaneiros especiais e estabeleceu-se um regime de câmbio com taxas flutuantes. (Barros et al., 1996 e Kume et al. 2000). 
Com a posse do novo governo em 1990, promoveu-se uma reforma tarifária ainda mais profunda que a primeira, quando foi anunciado um cronograma de redução gradual das tarifas de todos os produtos. Esta foi planejada para ocorrer de maneira gradual entre 1991 e 1994, de modo que, ao final do período, a tarifa máxima deveria ser de 40\%. O cronograma de abertura foi mantido até outubro de 1992, quando ocorreu uma antecipação das reduções tarifárias previstas para 1993 e 1994, implicando uma redução de seis meses da conclusão de reforma.

Em agosto de 1993, o Cruzeiro Real foi implementado como parte do Plano Real, para a introdução, a partir de julho de 1994, do Real. Com o intuito de estabilizar o nível de preços, a partir de março de 1994, a condução da política de importações se voltou para esse objetivo, e várias alíquotas de produtos com participação elevadas nos índices de preços internos foram reduzidas para $0 \%$ ou 2\%. Em setembro de 1994 entrou em vigor, também antecipadamente, a Tarifa Externa Comum (TEC) do Mercosul, cuja vigência estava prevista, segundo o Tratado de Assunção, para janeiro de 1995. (Kume, 1996 apud Moreira, 1996).

Barros et al. (1996) coloca que a abertura comercial pode influenciar o nível do emprego industrial, basicamente pela produtividade ou pelo nível de produção doméstica. Com relação ao primeiro, a abertura pode facilitar ou estimular o progresso tecnológico e inovações organizacionais, levando ao crescimento desta, o que, para um dado nível de produção, implica queda no nível de emprego. Assim, a importância da abertura comercial para a queda do emprego industrial nesse período é proporcional à sua importância em explicar o crescimento da produtividade média do trabalho (mantendo o produto constante).

Com relação ao nível de produção doméstica, a abertura tem dois efeitos. Por um lado, pode estimular as importações levando a uma queda na produção doméstica. Por outro, a abertura pode estimular as exportações induzindo a um crescimento na produção doméstica. Assim, o impacto da abertura sobre a produção doméstica e, portanto, sobre o emprego industrial vai depender do seu efeito líquido sobre a diferença entre importações e exportações de produtos manufaturados. ${ }^{5}$

Os efeitos da abertura são potencialmente grandes. No período em estudo, a partir de 1990 observa-se um declínio contínuo do emprego industrial, em termos relativos e absolutos, assim como sua incapacidade de recuperação para uma trajetória de crescimento. Esta mesma redução no emprego industrial é observada na amostra acompanhada neste trabalho para o Rio Grande do Sul. O Gráfico 1 permite visualizar a trajetória em nível: mesmo com uma recuperação no final de 1994 e começo de 1995, observa-se uma tendência de queda ao longo dos anos com uma reversão desta após 1999. Ainda assim, o retorno não se dá no nível do começo da década.

Analisando as relações entre comércio e emprego no período entre 1990 e 1996, focando especificamente a abertura comercial, Moreira (1997) aponta que a indústria de transformação foi o setor mais atingido pela abertura. Decompondo a taxa de crescimento do emprego como igual à soma das taxas de crescimento do consumo doméstico e da participação da produção doméstica no consumo doméstico (o coeficiente doméstico) menos a taxa de crescimento da produtividade do trabalho conforme formulação sugerida por Krueger (1980), ${ }^{6}$ o autor aponta que o declínio no coeficiente doméstico, somado ao crescimento da produtividade, levou a uma queda de $1 \%$ no emprego no período de 1990 a 1995, resultado que fez com que a participação do setor no total do pessoal ocupado caísse cerca de $10 \%$.

5 Veja também Soares et al. (2001). Deve-se destacar que grande parte dos estudos sobre abertura comercial e mercado de trabalho foca o efeito nos rendimentos por grupo educacional, como pode ser visto no trabalho aqui citado.

6 Esta relação se deriva das taxas de crescimento das variáveis na identidade $N=C_{D} \cdot\left(Y_{D} / C_{D}\right) /\left(Y_{D} / N\right)$. 
Maia (2003), também citada por Soares et al. (2001), identifica, da mesma forma, um forte efeito negativo da abertura econômica e das importações sobre o emprego, usando uma metodologia de decomposição de variações do emprego baseada nas Matrizes Insumo-Produto do IBGE.

Os autores supracitados, em razão de suas estimações e análises referentes à primeira metade da década de 1990, apontam para um reduzido impacto da abertura no nível de emprego, contrário ao que popularmente se acredita.

\subsection{Criação e destruição de emprego e nível de abertura comercial}

Se por um lado a literatura se ateve em investigar como se comportou o emprego na indústria em razão da abertura comercial pelo qual o País passou na última década, o mesmo não pode ser dito sobre as relações entre criação e destruição de emprego e a abertura. Mesmo na literatura internacional - e experiências de liberalização, como a brasileira, ocorreram em diversos países em diferentes graus de intensidade -, estudos dessa natureza são escassos. Mais comum, entretanto, são as análises referentes ao comportamento da criação e da destruição de emprego para diferentes níveis de exposição dos setores industriais à competição internacional, seja por um elevado nível das exportações em relação à produção doméstica, seja pela penetração das importações no mercado doméstico, independentemente dos efeitos que podem ser gerados pelo processo de abertura em si (ver, por exemplo, Roberts e Tybout, 1996).

Motivados pelo debate sobre o impacto que a competição internacional pode representar sobre os empregos norte-americanos e a estabilidade destes, Davis et al. (1996) analisaram as relações entre JC e JD e o nível de exposição dos setores da indústria americana ao comércio internacional. Classificando os setores em 4 dígitos, tanto pelo nível de penetração dos produtos importados quanto pelo coeficiente de exportação (exportações como fração da produção doméstica), os autores não encontraram nenhuma relação sistemática entre criação, destruição, crescimento líquido e realocação bruta do emprego e o nível de abertura do setor. Somente a destruição de empregos em setores com alto nível de penetração das importações (acima de 13,1\%), estimada em 12,2\%, sugere que o comércio internacional pode ser uma fonte de redução da segurança em se manter o posto de trabalho. Além de apresentar a maior taxa de destruição de emprego, esses setores também apresentam a maior taxa de realocação do emprego e a menor taxa de crescimento do emprego.

Baseados na teoria do capital humano, segundo a qual os empregadores estabelecem vínculos mais duradouros com trabalhadores mais qualificados, já que o custo de preencher uma vaga com o empregado adequado é mais alto e o tempo de procura maior, e no fato de que os setores com maior nível de penetração das importações nos EUA são os que pagam os menores salários e empregam os trabalhadores menos qualificados, os autores sugerem que estes setores são os mais propensos a apresentar maiores níveis de realocação bruta dos empregos. Apresentam ainda evidência a favor, controlando pelo salário, ao não encontrar relação significativa entre o excesso de realocação bruta e as classificações para importação e exportação. Isso indicaria que indústrias com alta penetração das importações nos EUA apresentam maiores taxas de realocação em razão da menor qualificação média de seus empregados, e não porque a competição internacional as expõem a inesperados choques externos.

Levinsohn (1999) estimou taxas de criação, destruição e realocação bruta do emprego para o Chile entre os anos 1980 e 1986, dividindo as empresas em exportadoras e importadoras. Nas estimativas ano a ano não se observou um grande crescimento do emprego no grupo exportador e uma

7 Para os setores classificados em níveis menores de penetração das importações, o maior valor para JD é estimado em 10,2\% e o menor em 9,5\%. 
redução do setor com maior penetração das importações. O autor entende que esse padrão é consistente com a idéia de que os efeitos da liberalização já teriam se dado em grande parte até $1979,{ }^{8}$ sendo desde então o câmbio o grande fator de influência internacional. Essa idéia é corroborada quando se verifica que a proporção do emprego nos setores tradables em relação aos non-tradables aumenta ou diminui de acordo com a apreciação ou depreciação do câmbio defasado em um período. Em anos que o câmbio apreciou, no ano seguinte o autor verificou um aumento da proporção dos empregos no grupo non-tradable; e nos anos em que o câmbio depreciou, foi verificado no ano seguinte um aumento da proporção dos empregos no grupo tradable.

\subsection{Evidências para o Rio Grande do Sul}

Para avaliarmos o comportamento das taxas de crescimento líquido e da criação, destruição e realocação do emprego segundo o nível de influência e exposição ao comércio internacional, também classificamos os setores em 3 grupos. Baseamos essa divisão na classificação proposta por Gourinchas (1998), que é similar à de Davies et al. (1996). Para aqueles autores os setores são considerados expostos ao comércio (ditos tradables) seja pelas exportações, seja pelas importações. Um setor será considerado tradables se o coeficiente de exportação (exportações sobre produção do setor) for superior a $13 \%$ ou se a penetração das importações exceder $12,5 \%$ em todos os trimestres da amostra. Já os setores não expostos ao comércio (ditos non-tradables) serão aqueles nos quais a penetração das exportações é inferior a 1,3\% ou a penetração das importações é inferior à 6,8\% em todos os trimestres da amostra. Note-se que há setores que não serão classificados nem como tradables nem como non-tradables. A partir de nossos dados, no grupo de setores tradables estão os setores de Material Elétrico e de Comunicações (devido à grande penetração das importações) e de Metalurgia e de Calçados (devido à grande índice de exportações). Já no grupo non-tradables foi identificado apenas o setor de Bebidas.

Analisaremos daqui para frente cada um desses três setores separadamente, começando com o setor tradable via penetração das importações (Material Elétrico e de Comunicações) na Tabela 4. Como mencionado, a reforma tarifária brasileira concentrou-se na primeira metade dos anos 1990. Para os anos de 1992 a 1995, o setor teve taxas de crescimento líquido do emprego positivas para o primeiro e o último ano e taxas negativas para 1993 e 1994 . Neste setor, a tarifa efetiva média de 27,6\% no primeiro trimestre de 1991 foi reduzida para $14,7 \%$ no último trimestre, ${ }^{9}$ com as quedas mais acentuadas estando concentradas em 1992 e 1993. Dada a acentuada redução de tarifas, a apreciação cambial em julho de 1994 e o conseqüente acentuado aumento da penetração das importações, seria de se esperar que esses anos apresentassem, em princípio, forte queda no nível de emprego desse setor.

8 Não é possível afirmar, categoricamente, com as estimações apresentadas no artigo, que esse efeito já havia se processado no início dos anos 1980. Mesmo porque a reforma tarifária se deu entre 1975 e 1979, sendo que enquanto em 1977 as tarifas variavam de $10 \%$ a 35\%, em 1979, exceto para veículos automotores, uma tarifa uniforme de $10 \%$ foi implementada.

9 Estando a política de importações subordinada ao objetivo de estabilização dos preços, a partir de março de 1994 alíquotas de vários produtos com participação elevada nos índices de preços internos foram reduzidas para $0 \%$ ou $2 \%$, dentre os quais estavam incluídos aparelhos eletrônicos (apesar de vários desses produtos terem tido aumentos em suas alíquotas ao longo de 1995). 
Tabela 4 - Fluxos de emprego (\%) de setores selecionados

\begin{tabular}{|c|c|c|c|c|c|c|c|c|c|c|}
\hline \multirow[b]{2}{*}{ ANO } & \multicolumn{5}{|c|}{$\begin{array}{l}\text { Tradable por penetração importações } \\
\text { (Material Elétrico e de Comunicações) }\end{array}$} & \multicolumn{5}{|c|}{$\begin{array}{l}\text { Tradable por exportações } \\
\text { (Metalurgia e Calçados) }\end{array}$} \\
\hline & $\mathrm{JC}$ & $\mathrm{JD}$ & NEG & GJR & EJR & $\mathrm{JC}$ & $\mathrm{JD}$ & NEG & GJR & EJR \\
\hline 1992 & 5.38 & 1.70 & 3.68 & 7.07 & 3.39 & 5.21 & 6.89 & -1.68 & 12.11 & 10.42 \\
\hline 1993 & 5.03 & 5.52 & -0.484 & 10.55 & 10.07 & 11.17 & 5.48 & 5.69 & 16.65 & 10.96 \\
\hline 1994 & 4.18 & 4.56 & -0.378 & 8.74 & 8.36 & 7.16 & 5.77 & 1.39 & 12.93 & 11.54 \\
\hline 1995 & 3.24 & 2.83 & 0.411 & 6.07 & 5.66 & 6.61 & 3.13 & 3.48 & 9.73 & 6.25 \\
\hline 1996 & 0.50 & 9.84 & -9.34 & 10.34 & 1.00 & 3.74 & 7.93 & -4.19 & 11.66 & 7.47 \\
\hline 1997 & 0.69 & 3.88 & -3.19 & 4.56 & 1.37 & 3.61 & 7.97 & -4.36 & 11.57 & 7.21 \\
\hline 1998 & 3.80 & 6.10 & -2.30 & 9.89 & 7.59 & 1.70 & 11.36 & -9.67 & 13.06 & 3.40 \\
\hline 1999 & 5.86 & 5.09 & 0.77 & 10.95 & 10.18 & 6.60 & 4.95 & 1.65 & 11.54 & 9.89 \\
\hline 2000 & 6.85 & 2.67 & 4.18 & 9.52 & 5.35 & 7.14 & 1.66 & 5.47 & 8.80 & 3.33 \\
\hline Média & 3.95 & 4.69 & -0.74 & 8.63 & 5.89 & 5.88 & 6.13 & -0.25 & 12.01 & 7.83 \\
\hline d. padrão & 2.19 & 2.41 & 4.03 & 2.23 & 3.46 & 2.74 & 2.86 & 5.14 & 2.22 & 3.11 \\
\hline
\end{tabular}

Fonte: FIERGS - Pesquisa Indicadores Industriais - CNI. Cálculos dos autores.

Tabela 5 - Fluxos de emprego (\%) de setor non-tradable (Bebidas)

\begin{tabular}{lcrrrr}
\hline & JC & JD & NEG & GJR & EJR \\
\hline 1992 & 0.68 & 9.98 & -9.31 & 10.66 & 1.35 \\
1993 & 2.77 & 6.12 & -3.35 & 8.88 & 5.53 \\
1994 & 1.80 & 15.81 & -14.01 & 17.61 & 3.61 \\
1995 & 2.53 & 9.86 & -7.33 & 12.39 & 5.06 \\
1996 & 4.58 & 14.43 & -9.86 & 19.01 & 9.15 \\
1997 & 25.47 & 5.91 & 19.57 & 31.38 & 11.81 \\
1998 & 11.61 & 5.82 & 5.79 & 17.42 & 11.63 \\
1999 & 1.60 & 14.28 & -12.68 & 15.88 & 3.20 \\
2000 & 5.96 & 16.01 & -10.04 & 21.97 & 11.92 \\
Média & 6.33 & 10.91 & -4.58 & 17.24 & 7.03 \\
Desvio padrão & 7.90 & 4.33 & 10.81 & 6.75 & 4.14 \\
\hline
\end{tabular}

Fonte: FIERGS - Pesquisa Indicadores Industriais - CNI. Cálculos dos autores.

Entretanto, apenas em dois anos foram estimadas taxas negativas de crescimento, e mesmo assim bastante modestas. Mas se até 1995 a abertura aparentemente não causou maiores impactos na taxa de crescimento do emprego, para 1996 estimou-se uma redução líquida do emprego de 9,0\% no setor. Esta queda, mesmo devendo-se, em parte, a uma redução de 2 pontos porcentuais da taxa de criação do emprego, explica-se pelo aumento acentuado da taxa de destruiçãa do emprego, que de $3 \%$ no ano anterior passou a $10 \%$. O “boom" de consumo ocorrido nos dois primeiros anos do Plano Real pode ter aumentado a demanda por bens produzidos nesses setores, principalmente quando se leva em consideração que aparelhos eletrônicos estão incluídos neste segmento, o que explicaria, apesar do crescimento da penetração das importações, a queda da taxa de crescimento de emprego somente em 1996.

Um último aspecto importante ao longo da década que se percebe neste setor (Material Elétrico e de Comunicação) são as taxas de realocação bruta e de excesso de realocação do emprego. Comparado a outros setores, a primeira $(G J R)$ é a segunda mais baixa $(8,63 \%)$, enquanto que a 
segunda (EJR) é a sexta mais alta (5,89\%) em 17 setores. Dado que, sob a ótica das importações, esse é o setor mais aberto, e dadas as mudanças cambiais e de tarifas, o esperado seria um maior nível de "turbulência" na realocação dos empregos neste quando comparado a outros setores, o que não se verifica.

$\mathrm{Na}$ Tabela 4 também constam os fluxos de emprego dos setores tradable pelas exportações. Este é composto pelos setores de Calçados e Metalurgia. É importante mencionar que ambos não possuem um padrão de crescimento contínuo de suas exportações ao longo da década de $1990{ }^{10}$ com ambas alternando períodos de expansão e de retração no valor total das vendas externas.

O crescimento líquido do emprego médio anual foi estimado em -0,25\%. Apesar de negativo, esse crescimento é consideravelmente menor do que o estimado para todos os setores, calculado em $-1,27 \%$. Mesmo sendo o crescimento médio negativo, ao longo do tempo alternam-se períodos de crescimento positivo e negativo dessas taxas, sendo que de 1996 a 2000 o padrão é o mesmo que o encontrado no setor com alta penetração das importações. Ao longo desses anos, a taxa de crescimento líquido de emprego é explicada por trajetórias opostas das taxas de JC e JD.

Como se trata de um setor em que as exportações têm um papel importante, o câmbio tem bastante influência. Percebe-se que os anos de menor criação e de maior destruição de empregos são os anos de apreciação do Real, e os anos de maior criação e menor destruição (1999 e 2000) são os anos em que o câmbio estava depreciado. Como o emprego industrial está diretamente associado ao nível de demanda para com a indústria, ${ }^{11}$ e o câmbio está diretamente ligado ao preço para compradores no exterior, é bastante razoável assumirmos que o câmbio desempenhou um papel importante na trajetória dessas taxas. Isto será estudado a fundo na seção seguinte.

Da realocação bruta do emprego, a taxa de $12,01 \%$ na média dos setores de Calçados e de Metalurgia é maior do que a taxa média estimada para toda a amostra, de 11,57\%. Como neste setor de característica exportadora encontra-se o setor de Calçados, e o Vale dos Sinos no Estado do Rio Grande do Sul concentra $80 \%$ das exportações, ${ }^{12}$ e em razão das grandes variações cambiais ocorridas ao longo da década de 1990 - em 1993 houve um pico de exportação em virtude da situação extremamente favorável do câmbio -, estas evidências sugerem um papel importante do câmbio nessa turbulência.

Até aqui temos considerado o papel do câmbio na alteração de preços relativos e sua conseqüência sobre a demanda desses produtos em setores mais abertos ao mercado internacional, seja pelas importações, seja pelas exportações. Tendo em vista a ênfase dada a esse aspecto, quando analisamos o setor de bebidas, o único classificado como non-tradable (Tabela 5), sobressai a não relação entre apreciação/depreciação cambial e a redução/aumento da taxa de crescimento líquida de emprego. Em razão de o setor ser pouco aberto ao mercado externo, o esperado seria, de fato, uma baixa correlação entre os movimentos dos fluxos de emprego e da taxa de câmbio. De fato, as estimativas apresentadas corroboram a idéia de não existência dessa correlação.

Mesmo "isolado" do efeito da abertura, o setor apresentou uma taxa média de crescimento do emprego líquido de $-4,58 \%$. Bastos (2000), estimando o crescimento da produtividade dos setores da indústria de transformação no Rio Grande do Sul com dados da PIM-PF e da RAIS-TEM, encontrou, para os anos de 1989 a 1997, um crescimento médio da produtividade da ordem de 6,94\% ao ano. Também estimando a produtividade, Moreira (1996) se depara com um crescimento

10 Entretanto, o coeficiente de exportação do setor de Calçados apresenta uma tendência de crescimento a partir de 1995, com um pico de subida após a depreciação do câmbio, no primeiro trimestre de 1999.

11 Veja Barros et al. (1996) para uma exposição mais detalhada acerca dessa característica na indústria.

12 Noronha e Turchi (2002) desenvolvem um estudo do complexo coureiro-calçadista no Brasil, no qual os autores descrevem informações referentes ao emprego e à importação e exportação no setor. Os autores também apontam para a sensibilidade do mercado calçadista às variações no câmbio. 
de 40\% desta entre os anos de 1990 e 1995 para o setor no Brasil. Este acentuado crescimento da produtividade sugere uma contrapartida na redução do emprego que pode explicar a taxa média de crescimento negativa estimada. Ainda sobre os fluxos de emprego, o setor apresenta uma taxa média de realocação bruta do trabalho estimada em $17,24 \%$, bastante elevada quando comparada aos setores tradables.

Para uma melhor visualização e comparação dos fluxos de emprego dos setores tradable e non-tradable, apresentamos nos Gráficos 1 e 2 as taxas de crescimento líquido e realocação bruta do emprego. Em NEG, o destaque é para a maior volatilidade dessa taxa no setor tradable (via importação e exportação). Além dessa maior variabilidade, no segundo gráfico o nível de realocação do setor non-tradable é maior do que o do setor tradable em quase todo o período estimado. Em virtude da redução das tarifas de importação e das variações cambiais da década, estes indicariam maiores níveis de mudanças e ajustes no setor tradables, tudo o mais constante. A evidência oposta apresentada nos gráficos sugere que outros fatores além destes dois mencionados podem ter um papel decisivo no nível de realocação.

Dentre as variáveis coletadas na Pesquisa Indicadores Industriais CNI, além do valor total das vendas das empresas, estão discriminadas as vendas para o próprio Estado, para o resto do País e para o exterior. Esta última variável, em particular, é de especial interesse por permitir um exercício interessante: dividindo as exportações pelo total das vendas, obtemos o porcentual exportado pela empresa. De forma a avaliar o comportamento de emprego de acordo com o nível de inserção da empresa no mercado internacional, separamos o primeiro e último decil pelo porcentual exportado, e para cada um calculamos estes fluxos (Tabela 6). Nessa estimativa, o setor a que a empresa pertence não é levada em conta.

Dois aspectos, ambos relacionados ao câmbio, sobressaem-se quando da comparação com as empresas classificadas pelos setores tradables e non-trabables (Tabelas 4 e 5). Verifica-se, primeiramente, que enquanto no primeiro grupo - empresas com menor relação exportação/vendas no mercado doméstico - não se observa um padrão de correlação entre câmbio e taxa de crescimento do emprego, no grupo mais exportador esse padrão é claro. Em segundo lugar, no grupo de empresas expostas à competição (último decil) de 1996 a 1998 as taxas de NEG foram negativas, tornando-se positivas nos dois últimos anos, com crescimento de JC e baixos níveis de JD.

O decil superior das empresas classificadas por nível de exportação apresentam taxa média de crescimento do emprego de $0,61 \%$, enquanto que os setores classificados aqui em tradables em razão das exportações tiveram essa taxa estimada em -0,25\% - tradables por importação e non-tradables apresentaram taxas menores. Os valores encontrados são uma fraca evidência de que empresas voltadas à exportação apresentam maior capacidade de expansão do que outras empresas.

Apesar de não tabelado, a classificação pelo primeiro e último decil evidenciou medidas significativamente diferentes em relação ao tamanho das empresas. Enquanto o grupo classificado no primeiro decil apresentou um nível médio de pessoal ocupado de 115 empregados, esse número é de 728 no último decil. Uma vez que a inserção em mercados internacionais via exportações envolve um custo fixo (este certamente maior do que para a compra de produtos importados), essa evidência sugere que o custo financeiro, operacional e organizacional é tal que afeta de forma significativa o perfil no referente ao porte da empresa, das indústrias que conseguem se estabelecer como exportadoras. 
Gráfico 1 - Taxa de crescimento líquido do emprego no grupo tradable e non-tradable

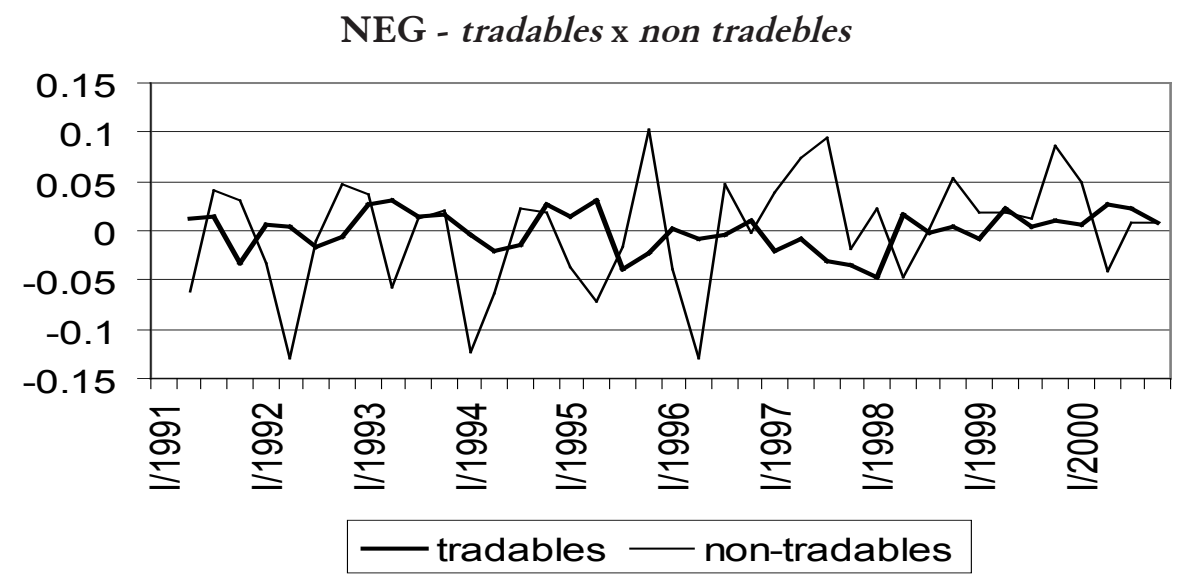

Fonte: FIERGS - Pesquisa Indicadores Industriais - CNI. Cálculos dos autores.

Gráfico 2 - Taxa de realocação bruta do emprego no grupo tradable e non-tradable

\section{GJR - tradables $\mathrm{x}$ non tradebles}

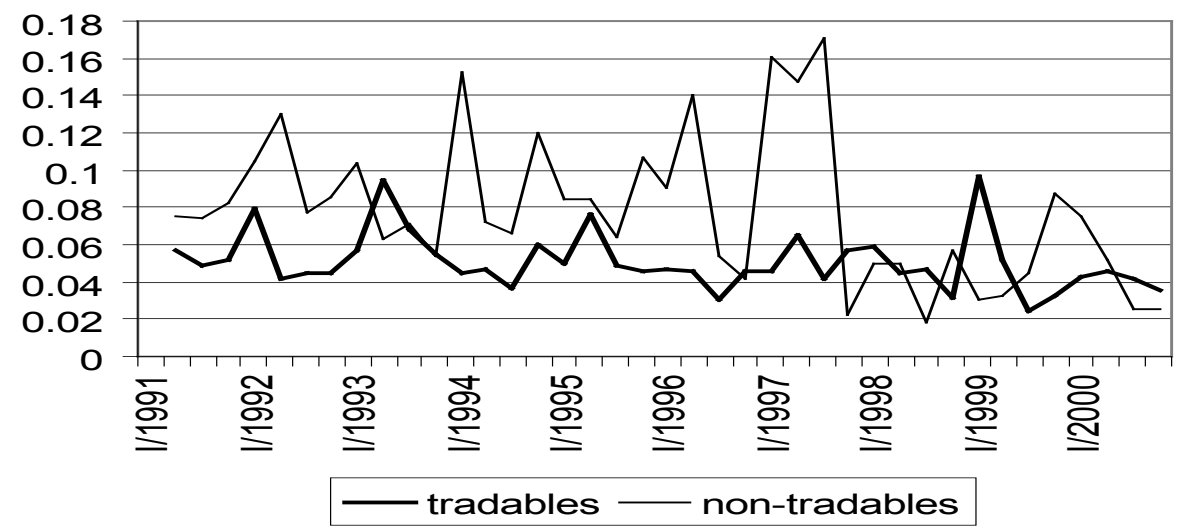

Fonte: FIERGS - Pesquisa Indicadores Industriais - CNI. Cálculos dos autores. 
Tabela 6 - Fluxos de emprego (\%) para empresas selecionadas

\begin{tabular}{|c|c|c|c|c|c|c|c|c|c|c|}
\hline \multirow[b]{2}{*}{ ANO } & \multicolumn{4}{|c|}{ Empresas no primeiro decil $X / Y$} & \multirow[b]{2}{*}{ EJR } & \multicolumn{5}{|c|}{ Empresas no último decil $X / Y$} \\
\hline & $\mathrm{JC}$ & JD & NEG & GJR & & JC & JD & NEG & GJR & EJR \\
\hline 1992 & 2.56 & 9.34 & -6.78 & 11.91 & 5.13 & 9.56 & 2.88 & 6.68 & 12.43 & 5.75 \\
\hline 1993 & 6.22 & 6.51 & -0.29 & 12.73 & 12.44 & 9.31 & 2.74 & 6.57 & 12.05 & 5.48 \\
\hline 1994 & 4.05 & 5.63 & -1.58 & 9.69 & 8.11 & 1.92 & 7.25 & -5.33 & 9.17 & 3.84 \\
\hline 1995 & 5.10 & 5.57 & -0.47 & 10.66 & 10.20 & 3.88 & 4.82 & -0.94 & 8.69 & 7.76 \\
\hline 1996 & 3.97 & 9.57 & -5.60 & 13.54 & 7.95 & 4.59 & 5.60 & -1.01 & 10.18 & 9.18 \\
\hline 1997 & 6.75 & 5.28 & 1.47 & 12.03 & 10.56 & 4.85 & 4.87 & -0.0209 & 9.73 & 9.70 \\
\hline 1998 & 2.44 & 4.96 & -2.52 & 7.41 & 4.88 & 0.96 & 14.88 & -13.92 & 15.83 & 1.92 \\
\hline 1999 & 1.70 & 5.25 & -3.55 & 6.95 & 3.40 & 7.91 & 1.38 & 6.52 & 9.29 & 2.77 \\
\hline 2000 & 5.11 & 4.09 & 1.01 & 9.20 & 8.19 & 8.54 & 1.63 & 6.91 & 10.17 & 3.26 \\
\hline Média & 4.21 & 6.25 & -2.03 & 10.46 & 7.87 & 5.72 & 5.12 & 0.61 & 10.84 & 5.52 \\
\hline d. padrão & 1.74 & 1.93 & 2.85 & 2.32 & 2.96 & 3.22 & 4.14 & 7.06 & 2.26 & 2.84 \\
\hline
\end{tabular}

Fonte: FIERGS - Pesquisa Indicadores Industriais - CNI. Cálculos dos autores.

\section{CÂMbIO E CRIAÇÃo E DESTRUIÇÃo DE POSTOS DE TRABALHO}

Na seção anterior descrevemos brevemente a abertura comercial e apontamos a importância do nível de abertura dos setores sobre as estimativas das taxas de criação e destruição de emprego, destacando o papel do câmbio nessa relação. Nesta seção abordaremos mais a fundo a importância do câmbio nessas taxas e investigaremos, de forma mais rigorosa, como se dá esse impacto.

\subsection{Literatura}

São poucos os trabalhos que tratam da relação câmbio-fluxos de trabalhadores. Gourinchas (1998) estima os impactos do câmbio nos fluxos de emprego na indústria norte-americana. O câmbio é interpretado como fonte de choques relocativos: a mudança cambial altera os preços relativos na economia, induzindo a mudanças de alocação dos fatores de produção para um novo ótimo. Para as estimativas de efeitos alocativos e agregados os setores são divididos em non-tradable, nos quais ou a penetração dos importados é baixa ou a proporção de produtos exportados é baixa e em tradable via penetração das importações ou pela quantidade relativa de exportações. Dessa forma, tem-se no primeiro grupo o de controle, e nos outros dois avaliam-se os efeitos relocativos do câmbio, enquanto os efeitos agregados são controlados pelas variações do emprego do total da indústria.

Os resultados encontrados indicam que a destruição de emprego nos setores tradables é bastante sensível aos movimentos do câmbio, varia negativamente e de forma significativa com os choques agregados e, independentemente do tipo de choque, JD é mais sensível do que a taxa de criação do emprego. Nos setores tradables, JC reduz-se moderadamente quando de uma depreciação do câmbio e aumenta em resposta a um choque agregado positivo. Ao se comparar JC e JD, após um choque agregado, ambos se movem em sentidos opostos, mas dado um choque cambial, as duas taxas movem na mesma direção. De fato, normalmente assume-se que choques relocativos induzem um crescimento positivo nas duas taxas, mas o autor estima que esse movimento positivo de ambos ocorre dentro (within) dos setores, diferentemente dos ajustes entre setores por vezes 
citados na literatura. Encontra-se também que períodos de depreciação no câmbio são tempos de "calmaria”, com redução tanto de JC e JD, enquanto que apreciações são caracterizadas por aumento da realocação. O artigo aponta ainda para a maior importância de JD do que de JC no ajuste de emprego na indústria e também que o excesso de realocação aumenta quando da apreciação do câmbio e diminui com a depreciação deste.

Para avaliar o impacto das flutuações cambiais na realocação do emprego entre e dentro dos setores da indústria na França, Gourinchas (1999) estima um modelo similar ao descrito acima. Nas estimações referentes à taxa de crescimento do emprego líquido, o autor aponta que $1 \%$ de apreciação do câmbio pode destruir até 35.000 empregos no setor tradable. Entretanto, a taxa de destruição na economia como um todo tende a ser menor se os empregos são criados em setores não expostos ao comércio internacional. Essa mudança líquida se dá por um simultâneo aumento de JD e por uma redução de JC. Os resultados também indicam que movimentos da taxa de câmbio não aumentam o nível de "turbulência" na economia francesa. Em particular, isto indica que a destruição de empregos que se seguiu à apreciação da moeda francesa nos anos de 1984 a 1992 não foram seguidos por uma subseqüente criação de empregos.

A realocação bruta de emprego se mostra menos sensível ao câmbio em setores da indústria com característica exportadora. O autor entende que uma possível explicação para este ponto esteja relacionada aos maiores custos de entrada desses setores. Por último, os resultados encontrados indicam que as variáveis de choques agregados e política monetária têm um impacto substancial em fluxos de emprego líquidos e na realocação bruta de empregos. Choques agregados positivos aumentam a criação de empregos e reduzem a destruição de empregos, enquanto o oposto se aplica à política monetária.

Avaliando o impacto do câmbio na criação e na destruição de emprego na indústria norteamericana nos anos de 1973 a 1993, Klein et al. (2000) destacam o papel da heterogeneidade entre as firmas em relação ao seu nível de exposição ao comércio internacional, seja pela penetração das importações ou pela importância das exportações nas vendas do setor. Partindo desse entendimento sobre o nível de abertura do setor em relação ao impacto do câmbio, os autores apresentam um modelo no qual tanto o nível de abertura da firma em relação à média do setor quanto o nível de abertura do setor são determinantes na magnitude e no sentido do impacto de flutuações cambiais. Uma vez fundamentado na firma, o modelo permite que haja simultaneamente criação e destruição de emprego dentro do mesmo setor. No caso de uma apreciação, uma firma mais aberta do que a média do setor reduzirá sua demanda por trabalho, enquanto que uma firma mais fechada aumentará essa demanda, o contrário ocorrendo no caso de uma depreciação da moeda.

Nas estimações, duas importantes assimetrias são identificadas nos resultados: primeiro, a destruição de emprego é sensível a movimentos da taxa de câmbio, mas a criação não parece ser; segundo, a taxa de destruição de empregos aumenta com a apreciação da moeda americana, enquanto que o contrário não se verifica.

Para uma apreciação de um ponto porcentual do câmbio, as estimações indicaram um aumento de $0,47 \%$ na taxa de destruição do emprego. Como os autores controlam para o nível de abertura, enquanto que para setores no quartil inferior uma apreciação de um ponto porcentual eleva em $0,4015 \%$ a taxa de destruição do emprego, para o quartil superior esse porcentual é estimado em $0,508 \%$, i.e., o impacto estimado no quartil superior é $22 \%$ superior ao estimado para o quartil superior de grau de abertura. 


\subsection{Resultados para o Rio Grande do Sul}

Na seção anterior, além de revermos o processo de abertura comercial brasileiro, analisamos o comportamento do emprego na indústria gaúcha nos setores mais abertos e nos mais fechados ao mercado internacional, destacando a possível importância do câmbio na explicação das taxas de criação e da destruição do emprego. Nesta seção, tendo o modelo teórico como referencial, investigaremos de forma mais rigorosa a importância do câmbio em JC e JD e no nível de realocação no mercado de trabalho na indústria do Rio Grande do Sul e de que forma o grau de abertura do setor é determinante nessa relação.

Dos 16 setores referentes ao Rio Grande do Sul, apenas 11 são considerados na estimação: Metalúrgica, Mecânica, Material Elétrico e de Comunicação, Material de Transporte, Madeira e Mobiliário, ${ }^{13}$ Borracha, Química, Têxtil, Calçados, Produtos Alimentares e Bebidas. Essa redução se mostrou necessária devido ao fato de nos dados de comércio exterior a classificação não ser a mesma que a utilizada na Pesquisa Indicadores Industriais CNI. Para os dados de comércio exterior (importação e exportação, especificamente), os dados foram obtidos no IPEA para todos os setores, exceto Calçados e Bebidas. Estes foram obtidos no sistema AliceWeb, mantido pelo MDIC. ${ }^{14}$

Um ponto central no modelo apresentado refere-se à abertura das empresas e do setor. Campa e Goldberg (1995) identificam 3 formas distintas de exposição de setores da indústria às flutuações do câmbio: por meio do nível das exportações relativo às vendas do setor, pela penetração das importações e pelo nível de insumos importados utilizados no setor. A indisponibilidade de dados que permitam a estimação da penetração das importações via insumos nos impede sua consideração. Trabalharemos aqui apenas com o nível de exportação e de penetração das importações dos setores, agregando-os, para estimarmos uma única medida de abertura do setor $\left(A_{i t}\right)$,

$$
A_{i t}=\left(X_{i t}+M_{i t}\right) /\left(Y_{i t}+M_{i t}\right)
$$

em que $X$ é o volume de exportações, $M$ o de importação e $Y$ é o volume de produção do setor e $i$ e $t$ denominam o setor e o trimestre, respectivamente. Para o nível de produção industrial não existem dados mensais ou trimestrais disponíveis. Sua obtenção se deu pela metodologia adotada por Haguenauer et al. (1998), ${ }^{15}$ utilizando índices de quantum e preços e tendo como ano base 1985, ano do último censo industrial. Estimado esse nível de produção e computados os níveis de exportação e importação, foi possível a estimação do nível de abertura descrito acima. O Gráfico 3 ilustra a evolução dessa variável ao longo da década de 1990.

13 Apesar de originalmente serem dois setores distintos, os dados referentes à importação e exportação agregam ambos, o que nos levou a agregar ambos em apenas um.

14 A página pode ser acessada no endereço www.portaldoexportador.gov.br

15 A metodologia para estimação do setor, baseada em Haguenauer et al. (1998) está disponível com os autores. 
Gráfico 3 - Grau de abertura setorial média - RS, 1991-2001

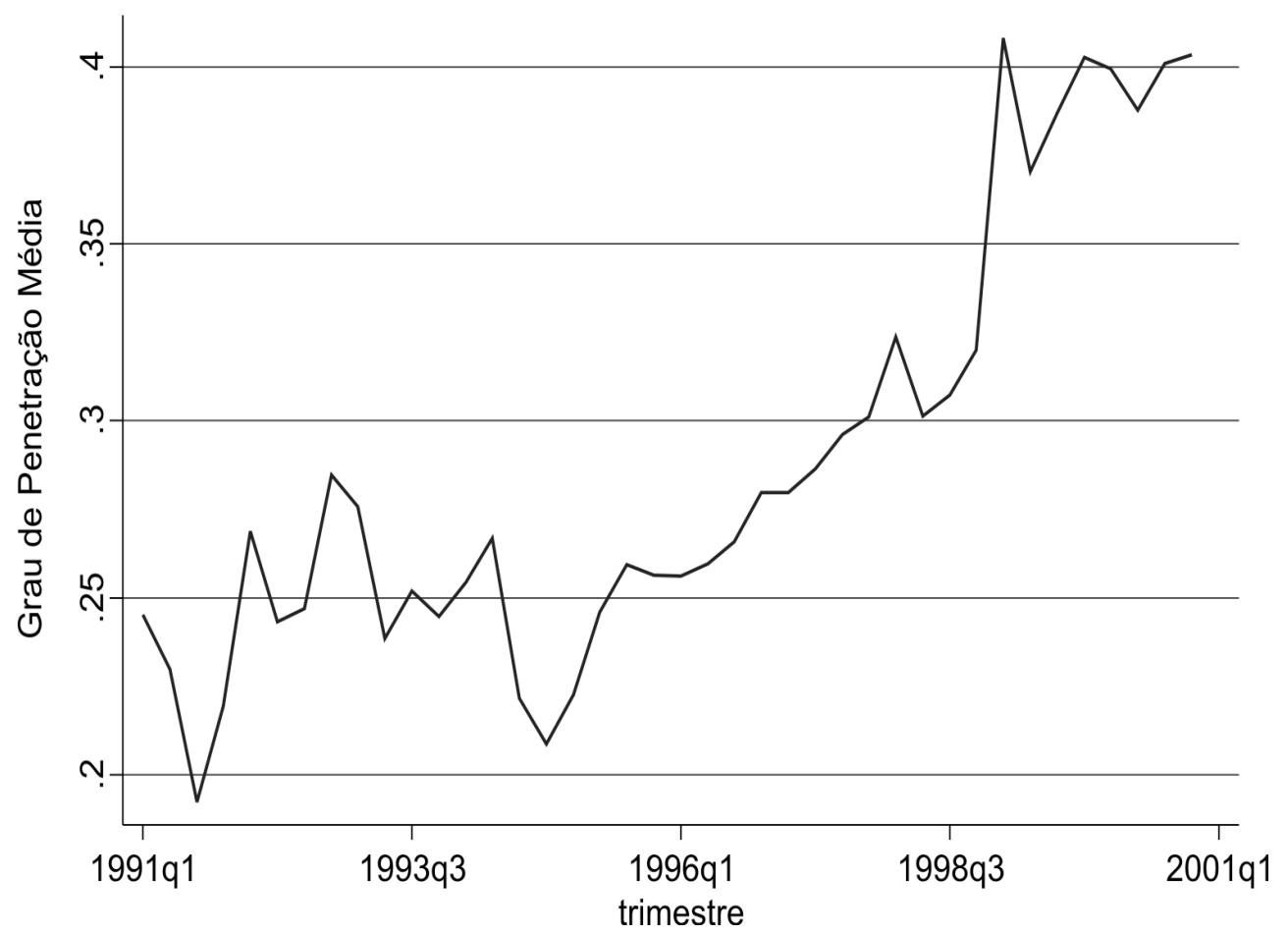

Fonte: Cálculos dos autores sobre dados do IBGE.

A implementação empírica direta do modelo usa dados setoriais. Dadas as suposições iniciais e a equação de demanda por produtos da firma $i$, em que o impacto do câmbio depende diretamente do nível de concorrência externa à qual a firma está exposta, todas as relações apresentadas a partir deste ponto mantêm essa interação entre as duas variáveis. Seguiremos então com a seguinte relação para a estimação:

$$
F_{i t}=\alpha_{i}+\beta_{1} \Delta r_{i t-1}+\beta_{2} \Delta(r * A)_{i t}+\beta_{3} \Delta A_{i t-1}+\beta_{4} \Delta y_{i t-1}^{B R}+\beta_{5} \Delta y_{i t-1}^{U S}+\beta_{6} \Delta w_{i t-1}+\varepsilon_{i t}
$$

em que $F=\{J C, J D, N E G, G J R\}, r$ é a taxa de câmbio real, $A$ o grau de abertura, como especificado acima, $y^{B R}$ o log do PIB do Brasil e $y^{U S}$ o log do PIB externo, representado pelo PIB dos EUA, sendo que as séries de ambos estão dessazonalizadas. Apesar de as exportações terem diferentes países como destino e as importações serem também advindas de diferentes regiões, em razão da dificuldade no acesso aos dados para ponderar o PIB externo pela importância comercial dos países utilizaremos como proxy para nível de atividade externa o PIB dos EUA, que possui grande influência no ciclo econômico mundial.

Para o (log) salários, $w$, utilizamos o salário contratual real médio, obtido da PIM-DG, calculado pelo IBGE. A base de dados disponível on-line permitiu a obtenção destes para a Região Sul. Dentre as variáveis da Pesquisa Indicadores Industriais CNI também são apurados o total dos salários e o total da folha de pagamento. Experimentamos ambas as bases das diferentes fontes nas estimações e os resultados não se modificaram. 
A seguir, apresentamos na Tabela 7 as taxas de crescimento médias e o desvio padrão das variáveis empregadas na estimação. No período em estudo, o câmbio se apreciou a uma taxa média de 0,57\% por trimestre e o PIB dos Estados Unidos cresceu a uma taxa maior do que o PIB Brasileiro, e a última das variáveis agregadas, o salário real contratual médio da Região Sul, cresceu a uma taxa média de $0,02 \%$ por trimestre.

Tabela 7 - Resumo das variáveis de 1991:1 a 2000:4 - em taxas de crescimento (\%), exceto grau de abertura

\begin{tabular}{lcc}
\hline Variáveis agregadas & Média & Des. Padrão \\
\hline Câmbio real (1) & 0.57 & 2.98 \\
PIB Brasil (2) & 0.008 & 0.02 \\
PIB EUA (3) & 0.009 & 0.005 \\
Salário real (2) & 0.02 & 0.13 \\
Variáveis do setor & & \\
NEG (4) & -0.12 & 3.31 \\
JC (4) & 3.42 & 1.84 \\
JD (4) & 3.54 & 1.81 \\
GJR (4) & 6.97 & 1.54 \\
Grau de Abertura (5) & 19.97 & 2.83 \\
\hline
\end{tabular}

Fonte: Cálculos dos autores baseado em dados do FMI (1), IBGE (2), BEA (3), FIERGS (4), SECEX/IPEA. (5)

Os fluxos de emprego e o grau de abertura são específicas de cada setor. A taxa média de crescimento do emprego líquido é negativa, sendo estimada em $-0,12 \%$ por trimestre. Essa taxa é resultante da diferença entre a criação e a destruição de emprego, respectivamente 3,42\% e 3,54\%. Das somas de ambas, tem-se a realocação bruta de emprego trimestral ao longo do período: 6,97\%. Por último, o grau médio de abertura do período foi estimado em 19,97\%, tendo esta variável apresentado uma trajetória de crescimento ao longo do período, principalmente a partir de 1995.

A Tabela 9 apresenta o resultado das estimações para os fluxos de emprego. Utilizamos um painel de efeitos fixos, no qual as diferenças entre os setores invariantes no tempo podem ser capturadas nos termos constantes. Os efeitos fixos resolvem problemas de endogeneidade de termos setoriais não observados, que podem criar estimadores inconsistentes na estimação com dados de cross-section ou séries de tempo. Várias especificações foram testadas, sendo que os resultados apresentados são os melhores modelos, levando-se em conta os sinais dos coeficientes, sua significância e $\mathrm{R}^{2}$.

Tanto o câmbio quanto o grau de abertura só se mostraram significativos quando defasados. Para todas as estatísticas de fluxos de emprego, exceto para realocação bruta, o efeito do câmbio se mostrou significativo. O efeito defasado do câmbio nos fluxos de postos de trabalho não é único na literatura. Tanto em Gourinchas (1998) como em Gourinchas (1999), o autor trabalha com polinômios para defasagem para o câmbio, sendo que no segundo o autor não considera o efeito do câmbio contemporâneo. O uso do câmbio defasado evita que mudanças no emprego afetem simultaneamente os preços relativos, reduzindo a possibilidade de endogeneidade. Desta forma, podemos tomar os choques do câmbio como exógenos ou, no mínimo, predeterminados. 
Tabela 8 - Resultados das regressões dos fluxos de emprego - indústria gaúcha, 1991-2000

\begin{tabular}{|c|c|c|c|c|c|c|c|c|}
\hline \multirow[t]{2}{*}{ Variáveis } & \multicolumn{2}{|c|}{$N E G$} & \multicolumn{2}{|c|}{$J C$} & \multicolumn{2}{|c|}{$J D$} & \multicolumn{2}{|c|}{ GJR } \\
\hline & Coef. & $\begin{array}{c}\text { Des. } \\
\text { Padrão }\end{array}$ & Coef. & $\begin{array}{c}\text { Des. } \\
\text { Padrão }\end{array}$ & Coef. & $\begin{array}{c}\text { Des. } \\
\text { Padrão }\end{array}$ & Coef. & $\begin{array}{c}\text { Des } \\
\text { Padrão }\end{array}$ \\
\hline Lag Câmbio Real & $0.198^{* *}$ & 0.088 & $0.101^{* *}$ & 0.051 & $-0.097^{*}$ & 0.056 & 0.004 & 0.061 \\
\hline Lag (Câmbio Real x G Abertura) & -0.178 & 0.227 & -0.151 & 0.132 & 0.027 & 0.144 & -0.124 & 0.157 \\
\hline Lag G Abertura & $0.033^{*}$ & 0.018 & 0.008 & 0.011 & $-0.025^{* *}$ & 0.012 & -0.017 & 0.013 \\
\hline PIB Brasil & $0.509^{* *}$ & 0.138 & $0.188^{* *}$ & 0.080 & $-0.321^{* *}$ & 0.088 & -0.132 & 0.096 \\
\hline PIB EUA & -0.273 & 0.410 & $-0.425^{\star}$ & 0.238 & -0.152 & 0.026 & $-0.577^{\star *}$ & 0.284 \\
\hline Salário Real & -0.003 & 0.016 & -0.011 & 0.009 & -0.008 & 0.010 & $-0.019^{*}$ & 0.011 \\
\hline Constante & $-0.014^{* *}$ & 0.006 & $0.025^{* *}$ & 0.004 & $0.039^{* *}$ & 0.004 & $0.064^{* *}$ & 0.004 \\
\hline$F(6,401)$ & \multicolumn{2}{|c|}{4.76} & \multicolumn{2}{|c|}{2.95} & \multicolumn{2}{|c|}{5.16} & \multicolumn{2}{|c|}{2.89} \\
\hline Prob $>F$ & \multicolumn{2}{|c|}{0.000} & \multicolumn{2}{|c|}{0.008} & \multicolumn{2}{|c|}{0.000} & \multicolumn{2}{|c|}{0.009} \\
\hline R2 & \multicolumn{2}{|c|}{0.053} & \multicolumn{2}{|c|}{0.031} & \multicolumn{2}{|c|}{0.064} & \multicolumn{2}{|c|}{0.041} \\
\hline
\end{tabular}

Em que: * para coeficientes significativos a $10 \% \mathrm{e}$ ** para coeficientes significativos a 5\%. Estimação por efeitos fixos. Variáveis explicativas em primeiras diferenças exceto Grau de Abertura. Painel de dados trimestrais, 1991/II - 2000/IV, para os seguintes setores: Metalúrgica, Mecânica, Material Elétrico e de Comunicação, Material de Transporte, Madeira e Mobiliário, Borracha, Química, Têxtil, Calçados, Produtos Alimentares e Bebidas. Fonte: cálculos do autor.

No efeito líquido do emprego (NEG), temos os seguintes resultados. O efeito de uma depreciação de $1 \%$ do câmbio implica um aumento (considerando o nível médio de abertura) de $0,16 \%$ do emprego líquido. Deste efeito, $0,19 \%$ se deve ao efeito direto do câmbio e -0,03\% ao efeito indireto associado ao grau de abertura externa, sendo o primeiro significativo a 5\%. O efeito direto do câmbio se mostra conforme o esperado: uma depreciação implica aumento do emprego líquido, e uma apreciação implica sua redução.

No que tange à criação de emprego, a princípio, para uma depreciação de $1 \%$ do câmbio, estimou-se um aumento de $0,07 \%$, sendo $0,10 \%$ devido ao efeito direto do câmbio e $-0,03 \%$ ao efeito indireto pela interação com o nível de abertura. Novamente, apenas o efeito direto se mostrou significativo (a 5\%), e assim uma depreciação de $1 \%$ do câmbio aumenta JC em 0,10\%. Já para a destruição de emprego, desconsiderando a significância dos coeficientes, o efeito de uma depreciação do câmbio de $1 \%$ foi estimado numa redução de JD de $0,092 \%$, o oposto ocorrendo no caso de uma apreciação. Apenas o efeito direto do câmbio mostrou-se significativo, sendo estimado o efeito sobre câmbio de uma queda da taxa de destruição em -0,097\%.

Em resumo, enquanto o efeito direto do câmbio foi significativo, e seu impacto teve o sentido esperado para a variação líquida de emprego, seu efeito indireto via interação com o nível de abertura não se mostrou significativo e teve sentido contrário ao esperado: quando de uma depreciação, setores mais abertos expandem menos seu emprego, e quando de uma apreciação, setores mais abertos contraem menos seu emprego. Quanto às taxas de criação e de destruição do emprego, para um impacto do câmbio, estas se movem em sentidos opostos, mas em níveis similares, o que implica uma certa simetria nos efeitos dos crescimentos e reduções de emprego nas empresas dos setores. Além disso, o efeito da interação não é significativo.

Nas estimações, o efeito direto do câmbio sobre a criação de emprego mostrou-se levemente mais sensível do que a destruição do emprego. O efeito indireto do câmbio pela interação com o grau de abertura também é significativo. No caso, o impacto de uma apreciação cambial para os 
setores no quartil superior do grau de abertura é estimado como sendo $22 \%$ maior do que para setores classificados no quartil inferior do grau de abertura.

Focando sob a ótica de choques relocativos e agregados, o segundo é controlado aqui pelas variações do PIB do País. Tanto para a variação líquida do emprego quanto para a criação e destruição de emprego, seus coeficientes são significativos a 5\%. Para um aumento de $1 \%$ do PIB, há um aumento de $0,19 \%$ em JC e uma redução de $0,32 \%$ em JD, levando a um aumento de $0,51 \%$ em NEG. Este resultado sugere que a resposta dos fluxos de emprego aos choques agregados se deve mais aos aumentos ou reduções da taxa de destruição do emprego do que da taxa de criação do emprego, embora estatisticamente não seja possível confirmar essa diferença.

As estimações conduzidas aqui para a realocação bruta de emprego não evidenciaram correlação significativa entre esta e mudanças no câmbio ou no PIB do País. A simetria entre os coeficientes de JC e JD faz com que os efeitos sobre a realocação se anulem. Mostraram-se significativos o PIB dos EUA e o salário real. O efeito do salário real foi negativo e significativo apenas na realocação. Isto sugere que os custos setoriais médios do emprego não têm efeito sobre o nível de emprego, mas apenas sobre sua realocação. O efeito negativo sobre a realocação sugere que períodos de aumento de salários reais são períodos de redução na heterogeneidade de comportamento do emprego em cada empresa. $\mathrm{O}$ fato de ser significativo apenas para a realocação exige mais pesquisas.

Em suma, as estimativas sugerem que há uma certa simetria no efeito do câmbio (defasado) e da abertura (defasada) sobre a criação e destruição do emprego setorial, com efeitos líquidos (NEG) positivos de ambos. Enquanto uma desvalorização cambial parece ter o efeito esperado de reduzir a destruição e aumentar a criação, o efeito positivo (negativo) sobre a criação (destruição) sugere que a medida de abertura está captando o grau de exportações entre os setores. Em relação às variáveis usuais na determinação do emprego - nível de atividade e custo do trabalho -, os resultados sugerem que o primeiro é importante para sua mudança líquida setorial, enquanto que o segundo possui apenas efeito sobre a heterogeneidade de comportamentos, reduzindo-a.

\section{COMENTÁRIOS FINAIS}

O presente trabalho teve seu foco no emprego da indústria do Rio Grande do Sul ao longo da década de 1990. Primeiramente, teve-se como objetivo mensurar e estudar os fluxos de emprego neste setor da economia, i.e., suas taxas de criação, de destruição, de crescimento líquido e de realocação bruta do emprego. Em segundo, com as grandes mudanças ocorridas neste período como pano de fundo, o trabalho buscou entender as relações e os impactos das variações da taxa de câmbio e da abertura comercial nos fluxos de emprego da indústria gaúcha.

Os resultados sugerem uma grande heterogeneidade no comportamento das empresas dentro dos setores, que não é captado por medidas de mudança líquida do emprego. A taxa média de crescimento líquido do emprego anual para a década foi estimada em $-0,4 \%$. O cálculo das taxas de criação $(6,08 \%)$ e das taxas de destruição $(6,48 \%)$ permitiu entender que, em todos os anos da década, sempre coexistiram, simultaneamente, a criação e destruição de postos de trabalho. Assim, mesmo em 1997 quando a taxa de crescimento líquido do emprego foi estimada em -5,42\%, a taxa de criação foi de aproximadamente $4 \%$. Em média, a taxa de realocação bruta do emprego foi superior a $12 \%$. Estes números sugerem que para cada emprego perdido líquido na indústria gaúcha no período cinco foram criados, mas seis foram destruídos, revelando a diversidade de comportamento das empresas estudadas. 
Em relação ao câmbio, a hipótese levada a cabo no trabalho é que este constitui essencialmente uma fonte de choques alocativos, em que o nível de abertura comercial do País é determinante no impacto advindo das suas flutuações. Esses choques, afetando a alocação ótima de recursos da firma, afetam a demanda de trabalho desta. No teste das relações entre câmbio e emprego, o impacto de uma depreciação de $1 \%$ da taxa de câmbio sobre as taxas de criação e destruição de emprego foi simétrico, em torno de $0,10 \%$ e com os sinais esperados (depreciação criando emprego e reduzindo a destruição). O impacto sobre a taxa de crescimento líquido do emprego, soma dos valores absolutos dos coeficientes de JC e JD, foi estimado em cerca de 0,20\%. É importante registrar que o impacto do câmbio foi estimado quando da defasagem deste em um trimestre, o que pode ser um indicativo do tempo necessário para ajustes à mudança dos preços relativos. Não foram identificados efeitos contemporâneos do câmbio sobre os fluxos de emprego, assim como não se identificou relação significativa da abertura comercial sobre estes. $\mathrm{O}$ nível de atividade tem uma elasticidade de 0,5 sobre a variação do emprego, em média, mas aumentos dos salários reais agregados não possuem efeitos sobre seu comportamento agregado, apenas sobre o grau de heterogeneidade da variação do emprego nas empresas, reduzindo-o, em média.

Em suma, o processo de abertura não parece ser responsável pela redução líquida de emprego no período, uma vez levada em conta o efeito negativo da apreciação cambial e o desaquecimento da economia.

\section{REFERÊNCIAS}

Barros, R. P.; Cruz, L. E.; Foguel, M.; Mendonça, R. O impacto da abertura comercial sobre o mercado de trabalho brasileiro. Série Seminários n 03/96, Rio de Janeiro: Diretoria de Pesquisa Seminários Sobre Estudos Sociais e do Trabalho IPEA - Instituto de Pesquisa Econômica Aplicada, jun. 1996.

Bastos, R. L. A. Emprego e produtividade na indústria de transformação do Rio Grande do Sul: alguns aspectos nos anos 90. Indicadores Econômicos FEE, Porto Alegre, v. 28, n. 1, p. 137-178, 2000.

Campa, J.; Goldberg, L. Employment versus wage adjustment and the U.S. dollar. Review of Economics and Statistics, v. 83, n. 3, p. 477-489, 2001.

Corseuil, C. H.; Ribeiro, E. P.; Santos, D. D.; Dias, R. Criação, destruição e realocação do emprego no Brasil. Texto para Discussão $n^{\circ}$ 855, Rio de Janeiro: IPEA - Instituto de Pesquisa Econômica Aplicada, jan. 2002.

Davis, S. J.; Haltiwanger, J. Gross job creation, gross job destruction, and employment reallocation. Quarterly Journal of Economics, 1992.

Davis, S. J., Haltiwanger, J. C.; Schuh, S. Job creation and destruction. Massachusetts: Institute of Technology, 1996.

Gourinchas, P-O. Exchange rates and jobs: what do we learn from job flows? NBER Macro Annual Conference, Cambridge, MA. 1998.

. Exchange rates do matter: French job reallocation and rxchange rate turbulence, 1984-1992. European Economic Review, 43, p. 1279-1316, 1999.

Greene, W. H. Econometric analysis. Prentice-Hall, 2000.

Haguenauer, L.; Markwald, R.; Pourchet, H. Estimativas do valor da produção industrial e elaboração de coeficientes de exportação e importação da indústria brasileira (1985-96). Texto para Discussão $n^{\circ} 563$, Brasília: IPEA - Instituto de Pesquisa Econômica Aplicada, jul. 1998.

Hamermemesh, D. Labor demand. Princeton: Princeton University Press, 1993.

Klein, M. W.; Schuh, S.; Triest, R. K. Job creation, job destruction and the real exchange rate. Working Paper, $n^{\circ}$ 7466, Cambridge, Massachusetts: National Bureau of Economic Research, jan. 2000. 
Konings, J. Job creation and job destruction in the UK manufacturing sector. Oxford Bulletin of Economics and Statistics, 57, p. 5-24, 1996.

Kume, H.; Piani, G.; Souza, C. F. A política brasileira de importação no período 1987-98: descrição e avaliação. Rio de Janeiro: IPEA, 2000. Mimeografado.

Levinsohn, J. Employment responses to international liberalization in Chile. Journal of International Economics, v. 47, n. 2, p. 321-44, 1999.

Maia, K. Os impactos do comércio internacional, da mudança tecnológica e da demanda final na estrutura de emprego no Brasil, 1985-1995. Economia Aplicada, FEA-USP/FIPE, v. 7, n. 2, p. 327-357, abr./jun. 2003.

Moreira, M. M. O impacto da abertura comercial sobre o emprego: 1990-1997. In: Giambiagi, F.; Moreira, M. M. A economia brasileira nos anos 90. Rio de Janeiro: BNDES, 1999.

Moreira, M. M.; Correa, P. G. Abertura comercial e indústria: o que se pode esperar e o que se vem obtendo. Textos para Discussão n ${ }^{\circ}$ 4, Rio de Janeiro: BNDES, Área de Planejamento Departamento Econômico - DEPEC, out. 1996.

Moreira, M. M.; Najberg, S. Abertura comercial: criando ou exportando empregos? Textos para Discussão $n^{\circ}$ 59, Rio de Janeiro: BNDES, Área de Planejamento Departamento Econômico - DEPEC, out. 1997.

Najberg, S.; Puga, F. P.; Oliveira, P. A. S. Criação e fechamentos de firmas no Brasil: (dez 1995/97). Texto para Discussão $n^{\circ}$ 79, Rio de Janeiro: BNDES, maio 2000.

Noronha, E. G.; Turchi, L. M. Cooperação e conflito: estudo de caso do complexo coureiro-calçadista no Brasil. Brasília: IPEA, 2002.

Pazello, E.; Bivar, W.; Gonzaga, G. Criação e destruição de postos de trabalho por tamanho de empresas na indústria brasileira. Rio de Janeiro, Pesquisa e Planejamento Econômico, v. 30, n. 2, ago. 2000.

Portugal, M.; Azevedo, A. Abertura comercial e política econômica no Plano Real, 1994-1999. In: Fontes e Arbex (eds.), Economia aberta - ensaios sobre fluxos de capitais, câmbio e exportações. Viçosa: UFV, 2000.

Revenga, A. Employment and wage effects of trade liberalization: the case of Mexico manufacturing. Journal of Labor Economics, v. 15, n.13, pt. 2, p. s20-s43, 1997.

Ribeiro, E. P. Rotatividade de trabalhadores e criação e destruição de postos de trabalho: aspectos conceituais. Texto para Discussão $n^{\circ}$ 855, Rio de Janeiro: IPEA - Instituto de Pesquisa Econômica Aplicada, out. 2001.

Roberts, M.; Tybout, J. Industrial evolution in developing countries: micro patterns of turnover, productivity and market structure. New York: Oxford University Press, 1996.

Soares, S.; Servo L. E.; Arbache J. O que (não) sabemos sobre a relação entre abertura comercial e mercado de trabalho no Brasil. Texto para Discussão n. 843, IPEA, 2001. 